\title{
Distinction between aleukaemic prodrome of childhood acute lymphoblastic leukaemia and aplastic anaemia
}

\author{
M M Reid, G P Summerfield
}

\begin{abstract}
Aims: To document the features of the socalled aplastic presentation of childhood acute lymphoblastic leukaemia (ALL) and to determine whether this prodrome can be distinguished from aplasia.

Methods: The peripheral blood and bone marrow appearances of all cases of childhood ALL presenting in one health region of England in 13 years and eight months were reviewed. All cases presenting with cytopenia without circulating blasts and marrow aspirates with no infiltrate of blasts were studied in detail.
\end{abstract}

Results: Four of $305(1.3 \%)$ children presented in this way. All four had reticulin fibrosis and increased cellularity in all or part of the marrow biopsy specimen. All were girls. Three had common and one surface membrane immunoglobulin positive ALL. Reassessment of this prodrome, by combining the features of four previously reported series of similar cases with the present one, highlighted the female preponderance (19 of 22 cases), bone marrow fibrosis (10 of 11 evaluable cases), prominent bone marrow lymphocytes (14 of 22 cases) and temporary recovery (all 12 evaluable cases). Six of 14 evaluable cases had bone marrow biopsy specimen appearances of apparently uniform hypocellularity, but only one of these did not have fibrosis.

Conclusions: If, in addition to an aspirate, a bone marrow trephine biopsy is carried out the prodrome can be distinguished from aplasia in most cases. The similarity of this prodrome to aplastic anaemia is merely superficial. Clinicians and morphologists may fail to appreciate the implications of this mode of presentation if the term "aplastic" continues to be used to describe this aleukaemic prodrome of ALL.

Haematology, Royal

Victoria Infirmary,

Queen Victoria Road,

Newcastle upon Tyne

NE1 4LP

M M Reid

Department of

Haematology,

Middlesbrough

General Hospital,

Middlesbrough,

Cleveland

G P Summerfield

Correspondence to:

Dr M M Reid

Accepted for publication

13 January 1992 early suggestion that aplastic anaemia might some children be preleukaemic, ${ }^{1}$ Melhorm $a l^{2}$ showed that "aplastic aneamia" in childhood which responded to steroids was in fact a precursor to ALL. Since then several series of similar $\operatorname{cases}^{3-5}$ and a number of individual case reports have been described. We present four more cases with a similar illness.

\section{Methods}

All cases of childhood ALL presenting in the northern health region of England since one of the authors (MMR) became involved in their diagnosis were studied. Between January 1978 and August 1991 four of $305(1.3 \%)$ cases first presented without peripheral blood or bone marrow evidence of leukaemia. Romanovsky stained bone marrow smears and bone marrow biopsy specimens stained with haematoxylin and eosin and with silver for reticulin were examined. Appropriate cytochemical stains confirmed the eventual diagnosis. Immunophenotyping was carried out by standard fluorescence techniques. Cytogenetic analysis of bone marrow cells was performed using standard $\mathrm{G}$ banding techniques.

\section{Case reports}

CASE 1

A 9 year old girl had a 12 month history of flitting joint pains diagnosed as seronegative polyarthritis. She was treated with salicylates but not with steroids. Six months before presentation she had a cellulitic-like lesion on her forehead, which resolved after treatment with co-trimoxazole, and erythema nodosum on her legs. Her initially normal haemoglobin concentration fell to $10 \mathrm{~g} / \mathrm{dl}$ and neutrophil count to $<2.0 \times 10^{9} /$. Platelet numbers remained normal. The liver and spleen were not enlarged. Bone marrow aspirate was hypocellular, with lymphocyte predominance and no blasts. A bone marrow biopsy specimen showed both hypo- and hypercellular areas with disorganised architecture, an infiltrate of lymphocytes, and a diffuse moderate increase in reticulin. Aplastic anaemia was excluded. Toxic damage, collagen vascular disease, and preleukaemia were considered. One month later the haemoglobin concentration was $9 \cdot 9$ g/dl, platelets $127 \times 10^{9} / 1$, and white cells $12 \times 10^{9} / 1$ with $50 \%$ blasts. A marrow aspirate showed $90 \%$ blasts, which were periodic acid Schiff (PAS) block positive and Sudan black negative. ALL (L1) was diagnosed. Immunophenotyping showed: Tdt $81 \%$, CD10 95\%, CD20 20\%, CD2 <1\%, surface membrane immunoglobulin (SMIg) $61 \%, \mu 51 \%, a, \gamma$, 
$\delta, \kappa, \hat{\lambda},<1 \%$. Cytogenetic analysis showed a 57 XX karyotype.

CASE 2

A 2 year old girl presented with malaise, pallor, and mouth ulcers but no enlarged liver or spleen. Haemoglobin was $5 \mathrm{~g} / \mathrm{dl}$, platelets $189 \times 10^{9} / 1$, and white cells $1.7 \times 10^{9} / 1$, with no neutrophils or blasts. A bone marrow aspirate was hypocellular with lymphocyte predominance and less than $5 \%$ blasts. A bone marrow biopsy specimen showed hypo- and hypercellular areas and an infiltrate of lymphocytes and other unidentifiable mononuclear cells. Reticulin was massively increased. Cytogenetic analysis of bone marrow failed. Aplastic anaemia was excluded. Toxic damage, nonhaemopoietic malignancy, and preleukaemia were considered. Raised urinary catecholamine metabolites led to a diagnosis of neuroblastoma. She was transfused. After further investigations, including computed tomography (not available on site at that time) and repeat catecholamine estimation, showed no abnormality. Initial treatment for neuroblastoma was stopped and she was observed. The blood count returned to normal. Six months later haemoglobin was $9 \mathrm{~g} / \mathrm{dl}$, platelets $44 \times 10^{9} /$, and white cells $64 \times 10^{9} /$, all of which were blasts. A bone marrow aspirate showed complete replacement with blasts, $10 \%$ with PAS block positivity, none positive with Sudan black. ALL (L1) was diagnosed. Immunophenotyping showed Tdt $95 \%$, CD10 92\%, CD19 88\%, CD2 <1\%, CD7 9\%, SMIg < $1 \%$. Cytogenetic analysis showed an apparently normal $46 \mathrm{XX}$ karyotype.

CASE 3

A 12 year old girl presented with malaise, pallor, and swellings at the angles of her jaw. Her haemoglobin was $5 \mathrm{~g} / \mathrm{dl}$, platelets $91 \times 10^{9} / 1$, and white cells $0.9 \times 10^{9} / 1$, with no neutrophils or blasts. A bone marrow aspirate was hypocellular. Most cells were lymphocytes. A bone marrow biopsy specimen showed hypo- and hypercellular areas with an infiltrate of lymphocytes. Reticulin was greatly increased in the cellular areas. Cytospin preparations of a collagenase digested biopsy core contained normal myeloid cells, megakaryocytes, a lymphocytic infiltrate ( $80 \%$ of cells) and $10 \%$ blasts. Immunophenotyping showed $<5 \%$ Tdt and CD10 positive cells. Cytogenetic analysis showed an apparently normal $46 \mathrm{XX}$ karyotype. Aplastic anaemia was excluded. Toxic damage, collagen vascular disorder, and preleukaemia were considered. A biopsy specimen of the facial swelling showed pus, no granulomata, and no sign of malignancy. She was transfused and observed. Two weeks later she had $5 \times 10^{9} / 1$ neutrophils and $300 \times 10^{9} / 1$ platelets. Four weeks after presentation blasts appeared in her blood. A bone marrow aspirate showed $90 \%$ blasts, which were negative on cytochemical staining. ALL (L1) was diagnosed. Immunophenotyping showed Tdt $80 \%$, CD10 97\%, CD19 96\%, CD7 2\%, SMIg $<1 \%$. Cytogenetic analysis showed four similar clones with 44 or 45 chromosomes, com- mon features being a ring $X$ and $i(9 q)$.

CASE 4

A 5 year old girl presented with fever, malaise, vomiting, pallor and drowsiness and later had a grand mal fit. Bilateral papilloedema with fundal haemorrhages was noted. Haemoglobin was $4 \cdot 2 \mathrm{~g} / \mathrm{dl}$, platelets $41 \times 10^{9} / 1$, and white cells $42 \times 10^{9} / 1$, with neutrophils $<2 \times 10^{9} / 1$ and no blasts. She had renal failure with a serum creatinine concentration of $426 \mu \mathrm{mol} / 1$. Klebsiella and a coagulase negative Staphylococcus were isolated from blood culture. A computed tomography scan showed mild hydrocephalus but no intracranial mass lesion. A bone marrow aspirate contained a few hypercellular particles and showed dyserythropoiesis, prominent lymphocytes, occasional aggregates of small mononuclear cells and $<5 \%$ blasts. A bone marrow biopsy specimen showed no evidence of aplastic anaemia, but contained an infiltrate of small cells and considerable fibrosis. Non-haemopoietic tumour and leukaemia were considered. Immunophenotyping of marrow cells showed Tdt $<1 \%$, CD10 < 1\%, CD19<1\%, CD2 $86 \%$. No cells expressed N-CAM (neural cell adhesion molecule). Cytogenetic analysis showed an apparently normal $46 \mathrm{XX}$ karyotype. No diagnosis was made and the cause of the lymphocytic infiltrate was unknown. She responded to intravenous fluids and antibiotics, received red cell and platelet transfusions, and, because of the raised intracranial pressure, was given a reducing course of dexamethasone. She made a complete clinical and haematological recovery. Eighteen months later haemoglobin was $9.6 \mathrm{~g} / \mathrm{dl}$, platelets $52 \times 10^{9} / 1$, and white cells $16 \times 10^{9} / 1$ with blasts $4 \times 10^{9} / 1$. A bone marrow aspirate contained $95 \%$ Sudan black negative blasts. ALL (L1) was diagnosed. Immunophenotyping showed Tdt $24 \%$, CD10 $>90 \%$, CD7 $<1 \%$, CD33 < $1 \%$, SMIg < $1 \%$. Cytogenetic analysis was unsuccessful.

All were treated according to Medical Research Council protocols, case 1 according to UKALL VIII, and cases 2-4 according to UKALL X. Remission was achieved in cases 1 , 2 , and 4. Cases 1 and 2 remained in first complete remission eight and five years after starting treatment. Case 3 responded but died of an Enterobacter septicaemia before remission was achieved. Case 4 had isolated central nervous system (CNS) relapse 15 months after diagnosis and remained alive but with persisting CNS disease five years after diagnosis.

\section{Discussion}

The four cases described here represent $1 \cdot 3 \%$ of all children with ALL diagnosed over a period of 13 years and eight months in one health region of England. All presented with anaemia (three severe) and varying degrees of neutropenia. Three had well preserved platelet counts. The time interval between first presentation to hospital and diagnosis of leukaemia ranged between four weeks and 18 months. All had an infiltrate of lymphocytes, 


\begin{tabular}{|c|c|c|c|c|c|c|c|c|c|c|}
\hline Study & $\begin{array}{l}\text { No of } \\
\text { cases }\end{array}$ & $\begin{array}{l}\text { No of } \\
\text { girls }\end{array}$ & Anaemia & $\begin{array}{l}\text { Neutro- } \\
\text { penia }\end{array}$ & $\begin{array}{l}\text { Platelets } \\
>100 \times 10^{4} / l\end{array}$ & $\begin{array}{l}\text { Platelets } \\
<40 \times 10^{4} / l\end{array}$ & $\begin{array}{l}\text { Marrow } \\
\text { lymphocytes }\end{array}$ & $\begin{array}{l}\text { Marrow } \\
\text { fibrosis }\end{array}$ & $\begin{array}{l}\text { Uniformly } \\
\text { hypocellular } \\
\text { biopsy } \\
\text { specimen }\end{array}$ & $\begin{array}{l}\text { Temporary } \\
\text { recovery }\end{array}$ \\
\hline $\begin{array}{l}\text { Melhorn et al }{ }^{2} \\
\text { Shackleford } e t \text { al }^{3} \\
\text { Sills and Stockman } \\
\text { Breatnach } \text { et al }{ }^{5} \\
\text { Present series } \\
\text { Total }\end{array}$ & $\begin{array}{r}6 \\
2 \\
2 \\
8 \\
4 \\
22\end{array}$ & $\begin{array}{r}5 \\
1 \\
2 \\
7 \\
4 \\
19\end{array}$ & $\begin{array}{r}6 \\
2 \\
2 \\
8 \\
4 \\
22\end{array}$ & $\begin{array}{r}6 \\
2 \\
2 \\
8 \\
4 \\
22\end{array}$ & $\begin{array}{l}3 \\
0 \\
1 \\
2 \\
3 \\
9\end{array}$ & $\begin{array}{l}2 \\
1 \\
0 \\
4 \\
0 \\
7\end{array}$ & $\begin{array}{r}1 \\
0 \\
1 \\
8 \\
4 \\
14\end{array}$ & $\begin{array}{ll}\left(^{\star}\right) \\
\text { ND } \\
\text { ND } \\
\text { ND } \\
6 & (7) \\
4 & (4) \\
10 & (11)\end{array}$ & 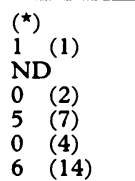 & $\begin{aligned}\left.{ }^{\star}\right) & \\
& (0) \\
1 & (1) \\
2 & (2) \\
7 & (7) \\
2 & (2) \\
12 & (12)\end{aligned}$ \\
\hline
\end{tabular}

( $\left.{ }^{\star}\right)$ Number of evaluable cases. ND not done or not reported. $\bullet$ One girl, given steroids before bone marrow examination, is not included.

not blasts, in the first marrow aspirate examined. Two had temporary recovery of blood counts before the diagnosis of leukaemia was made. Their prodrome is similar to that described in the previous series ${ }^{2-5}$ in several respects. We are reluctant to suggest that our four cases comprise yet another rare prodrome of ALL and suspect that they and the previously reported series are all examples of the same phenomenon.

Three of the present cases developed common ALL, as did all of those tested in one of the earlier series, ${ }^{5}$ but case 1 , some of whose details have been reported already, ${ }^{6}$ is unusual in that her blasts expressed surface $\mu$ chain without any of the other features of B-ALL. Too few cases have been described to exclude the possibility that null (as opposed to non-B, non-T) or T-ALL might present in this way. There is no evidence that these patients do any worse than average, provided they are not treated with steroids at the first presentation, but the numbers are small. The perceived benefit of response to steroids ${ }^{2}$ reflected an approach to diagnosis which existed before the widespread use of effective treatment for ALL, and is clearly outweighed by the risk of subsequent emergence of resistant leukaemia. Both children in this and the most recent series $^{5}$ who were treated with steroids had central nervous system relapses.

Some differences in interpretation of the presenting features between the present four children and those previously described prompted a reappraisal of this prodrome. The distribution of the major clinical features within the published series is shown in the table, together with those of the present one. Important features of the marrow in our cases are the increased cellularity in some areas in each child, and the increased reticulin. In two of the series $^{23}$ bone marrow trephine biopsies were either not done or not reported in most patients, but few centres would now make a diagnosis of aplastic anaemia without biopsy confirmation. In the group reported by Breatnach et $a l^{5}$ uniform hypocellularity was not confirmed in two of the seven with evaluable marrow biopsy specimens. If our cases are included only six of 14 evaluable patients had truly hypocellular bone marrow despite the meagre cellularity of the aspirated material. Fibrosis, present in 10 of the 11 evaluable cases, might have contributed to the poor cellularity of the aspirated marrow. Severe thrombocytopenia is not common and nine had platelet counts of $>100 \times 10^{9} / 1$ at presentation. In most cases, therefore, the similarity with aplastic anaemia was superficial once full investigation, including bone marrow biopsy, had been carried out.

Nineteen of the 22 cases ( $86 \%$; $95 \%$ confidence intervals $65-95 \%$ ) described in these five series have been girls. It seems unlikely that this disproportionate sex ratio is merely due to chance. Of equal interest is the temporary recovery of haemopoiesis without specific treatment observed in all 12 evaluable children. This behaviour may induce a false sense of security which may be transmitted to their families.

The pathogenesis of this prodrome is obscure. The rate of fibrosis is similar to that expected in childhood ALL of B lineage ${ }^{7}$ and may reflect reaction of bone marrow fibroblasts to occult lymphoblasts. This hypothesis could be examined in future cases by molecular techniques to detect minimal presenting (as opposed to residual) disease if bone marrow samples from the presenting illness and their subsequent ALL are stored. But what of the peripheral cytopenia documented in most cases? The recovery after blood transfusion resembles the behaviour of transient erythroblastopenia of childhood (TEC). Although TEC is not usually accompanied by severe neutropenia, and almost never by thrombocytopenia, human parvovirus B19 infection often is. ${ }^{8}$ Prolonged B19 infection with chronic failure of erythropoiesis does occur in some immune suppressed children, notably those already being treated for ALL, and one such case showed some response to treatment with infusions of immune plasma. ${ }^{9}$ Perhaps these children have an unusual complication of a common virus infection due to immune dysfunction before leukaemia is diagnosed. It remains possible that the rate of putative viral infection is similar in boys and girls but that development of frank leukaemia is delayed in girls by some other immunological mechanism. There are no data in this or the previous reports to advance hypotheses about pathogenesis beyond speculation. Virological, immunological, and bone marrow culture studies may offer clues in future cases if the importance of the presentation symptoms are appreciated.

In summary, the striking and most common features of this prodrome, other than its rarity 
(1-2\% of cases of childhood ALL), peripheral blood cytopenia, and the diagnostic problems it poses, are female preponderance, fibrotic bone marrow with lymphocytic, not blastic, infiltration, hypercellularity of some areas of the bone marrow of many cases and temporary recovery of the blood count. It should not be confused with the familiar picture of ALL presenting with few circulating blasts, because in such cases the diagnosis is usually obvious on first examination of the bone marrow, nor with aplastic anaemia. Perhaps the prodrome could more usefully be described as "aleukaemic" than as "aplastic". The difference is more than semantic. Prominence given to the term "aplastic" in earlier reports of this mode of presentation may mislead haematologists and clinicians and result in failure to appreciate the importance of a syndrome which few would now describe as "aplastic". It is a potentially recognisable preleukaemic prodrome in its own right.
We thank Ms E V Davison, N Bown, and Dr C Clarke for the cytogenetic analyses, the Tyneside Leukaemia Research Association for providing flow cytometry facilities and the Northern Registry for help with case ascertainment.

1 O'Gorman-Hughes DW. The varied patterns of aplastic anaemia in childhood. Aust Paediatr $\mathcal{F} 1961 ; 2: 228-36$.

2 Melhorn DK, Gross S, Newman AJ. Acute childhood leukemia presenting as aplastic anemia: The response to corticosteroids. $\mathcal{F}$ Pediatr 1970;77:647-52.

3 Shackleford GD, Bloomberg G, McAlister WH. The value of roentgenography in differentiating aplastic anemia from leukemia masquerading as aplastic anemia. $A m \mathcal{J}$ from leukemia masquerading as aplasic

4 Sills RH, Stockman JA. Preleukemic states in children with acute lymphoblastic leukemia. Cancer 1981;48:110-2.
a lic

5 Breatnach F, Chessells JM, Greaves MF. The aplastic presentation of childhood leukaemia: a feature of common-ALL. Br F Haematol 1981;49:387-93.

6 Reid MM. B-ALL without Burkitt characteristics in children. Br f Haematol 1988;69:574

7 Wallis JP, Reid MM. Bone marrow fibrosis in childhood acute lymphoblastic leukaemia. $f$ Clin Pathol 1989;42 $9-12$.

8 Young N. Hematologic and hemopoietic consequences of B19 parvovirus infection. Semin Hematol 1988;25: 159-72.

9 Kurtzman GJ, Cohen B, Meyers P, Amunullah A, Young NS. Persistent B19 parvovirus infection as a cause of severe chronic anaemia in children with acute lymphocytic leukaemia. Lancet 1988;ii:1159-62. 